\title{
THÉOPHILE GAUTIER, Critique théâtrale, t. XII mai 1854- août 1855
}

\section{Lise Sabourin}

\section{(2) OpenEdition}

\section{Journals}

Édition électronique

URL : https://journals.openedition.org/studifrancesi/44069

DOI : $10.4000 /$ studifrancesi.44069

ISSN : 2427-5856

\section{Éditeur}

Rosenberg \& Sellier

\section{Édition imprimée}

Date de publication : 1 juin 2021

Pagination : 231

ISSN : 0039-2944

\section{Référence électronique}

Lise Sabourin, "ThÉOPHILE GautIER, Critique théâtrale, t. XII mai 1854-août 1855 », Studi Francesi [En ligne], $193($ LXV | I) | 2021, mis en ligne le 01 juillet 2021, consulté le 15 octobre 2022. URL : http:// journals.openedition.org/studifrancesi/44069; DOI : https://doi.org/10.4000/studifrancesi.44069

Ce document a été généré automatiquement le 15 octobre 2022.

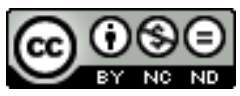

Creative Commons - Attribution - Pas d'Utilisation Commerciale - Pas de Modification 4.0 International - CC BY-NC-ND 4.0

https://creativecommons.org/licenses/by-nc-nd/4.0/ 


\title{
THÉOPHILE GAUTIER, Critique théâtrale, $t$. XII mai 1854-août 1855
}

\author{
Lise Sabourin
}

\section{RÉFÉRENCE}

THÉOPHILE GAUTIER, Critique théâtrale, t. XII mai 1854-août 1855, texte établi, présenté et annoté par P. Berthier, Paris, Honoré Champion, 2019, 782 pp.

1 Ce douzième tome de la Critique théâtrale de Gautier correspond à l'année 1854-1855, qui marque, comme le souligne la préface de Patrick Berthier (pp. 9-14), un important tournant dans sa carrière, puisqu'en avril 1855, après 741 feuilletons dramatiques en dix-huit ans à "La Presse", il passe au "Moniteur universel". La cause en est sans doute à chercher dans le caractère assez autoritaire mais pingre de Girardin, les contraintes familiales financières de Gautier redoublées par la mort de son père, mais aussi dans l'accumulation de quelques différends: Gautier remettait souvent tardivement ses textes, ce qui irritait Girardin forcé de décaler leur parution dans un contexte de concurrence entre journaux. Un clivage politique discret s'y est sans doute ajouté vis-àvis du nouveau régime en place: Girardin se sent forcé de plier plus qu'il n'adhère, alors que Gautier ne semble pas avoir eu de difficulté à entrer au journal officiel de l'Empire. Même si cela change quelque peu le domaine où peut s'exercer sa critique (puisque la musique, dévolue à Fiorentino, lui échappe désormais), Gautier n'en persiste pas moins dans ses habitudes de libre expression. Il se permet seulement quelques développements plus longs compensatoires à l'occasion.

2 Aussi ce tome nous permet-il toujours de percevoir le panorama des spectacles offerts aux Parisiens, et même aux Munichois puisque Gautier, pendant son voyage en Bavière en juillet-août 1854, rapporte ce qu'il a vu: Le Prophète de Meyerbeer, Emilia Galotti de Lessing, Faust et Egmont de Goethe.

Opéras et opéras-comiques continuent d'enchanter les soirées des mélomanes: La Reine d'un jour d'Adam sur livret de Scribe et Saint-Georges, La Fiancée du diable de Massé sur 
livret de Scribe et Romand, La Reine de Chypre d'Halévy sur texte de Scribe, L'Opéra au camp de Varney sur livret de Foucher. Gautier se fait aussi juge et partie en relatant la représentation de son ballet-pantomime, écrit avec Fanny Cerrito, Gemma, mis en musique par Gabrielli. Aux Italiens, on écoute Rossini (Sémiramis, Le Barbier de Séville), Verdi (Otello, Le Trouvère) et Bellini (Les Puritains), et on entend de nouveau chanter la Ristori dans Oreste et Mirra. Au théâtre Ventadour, on a le plaisir de voir succéder une troupe anglaise jouant Macbeth à la troupe italienne de Righetti qui a évoqué les Gelosi fortunati et joué Goldoni.

4 Au Théâtre-Français, Rachel reprend Marie Stuart puis Phèdre, et les contemporains font jouer leurs pièces nouvelles: La Czarine de Scribe, Péril en la demeure de Feuillet, Les Ennemis de la maison de Doucet, Par droit de conquête de Legouvé. Mlle George reprend Rodogune à l'odéon, qui vient de représenter Hamlet de Shakespeare et la Médée d'Hippolyte Lucas.

5 Le Gymnase crée Flaminio de Sand, Ceinture dorée d'Augier, Le Demi-Monde de Dumas fils, tandis que le Vaudeville et l'Odéon représentent Le Marbrier et La Conscience de Dumas père, puis la Gaîté son Retour du «Pharaon» en collaboration avec Maquet, qui de son côté fait jouer son Comte de Lavernie à la Porte-Saint-Martin. Augier crée son Mariage d'olympe et Théodore Barrière ses Parisiens de la décadence au Vaudeville, tandis que Frédérick Lemaître reparaît à l'Ambigu. Si l'on ajoute quelques comédies-vaudevilles de Labiche et Marc-Michel (par exemple, Les Précieux au Palais-Royal) et les habituels numéros du Cirque et de l'Hippodrome, on voit que les plaisirs ne manquent pas en cette année de l'Exposition Universelle à Paris. Les premières cavalcades d'Orléans en l'honneur de Jeanne d'Arc donnent encore l'occasion d'une excursion en chemin de fer pour assister au magnifique défilé en habits médiévaux.

6 Mais Gautier a également lieu d'être peiné par la mort de Nerval qu'il annonce le 30 janvier 1855 et consacre un bel article le 2 juillet à Delphine de Girardin qui s'est éteinte toujours en bienfaisante amatrice des lettres et des arts. En bon témoin du romantisme, qui commence ainsi à disparaître, il s'accorde une longue analyse de L'Enfance du Christ de Berlioz et quelques évocations des romans balzaciens au passage de ses recensions des nouvelles pièces de Dumas fils ou d'Augier. 